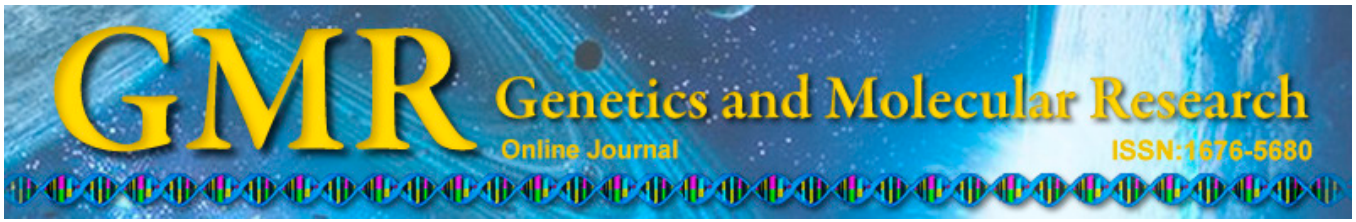

\title{
Comparative analysis of the river buffalo somatostatin gene
}

\author{
N.B. Stafuzza, M.M. Borges and M.E.J. Amaral \\ Departamento de Biologia, Instituto de Biociências, Letras e Ciências Exatas, \\ Universidade Estadual Paulista, São José do Rio Preto, SP, Brasil \\ Corresponding author: M.E.J. Amaral \\ E-mail: eamaral@ibilce.unesp.br
}

Genet. Mol. Res. 13 (4): 10017-10024 (2014)

Received May 7, 2014

Accepted October 2, 2014

Published November 28, 2014

DOI http://dx.doi.org/10.4238/2014.November.28.6

\begin{abstract}
The somatostatin protein plays a crucial role in the regulation of multiple biological functions, such as growth, fat deposition, and nutrient absorption in vertebrates. Polymorphisms in the somatostatin gene have been associated with growth traits in livestock species, including cattle and goat. In this study, we conducted complete molecular characterization of the somatostatin gene in Bubalus bubalis (Murrah breed) by sequencing a Murrah BAC clone spanning 72,489 base pairs (bp) in length. The buffalo somatostatin gene contains 1481 bp organized into a 5'-untranslated region (135 bp), exon 1 (139 bp), intron 1 (839 bp), exon 2 (212 bp), and 3'UTR (156 bp). Comparative analysis between the buffalo somatostatin DNA coding sequence and the amino acid sequence with other bovids (cattle, goat, and sheep), horse, pig, human, rodents (mouse and rat), and chicken. Identity varied from $83-99 \%$ on the DNA sequence level and $88-100 \%$ on the protein level. In addition, a comparison of gene sequences between Murrah and Mediterranean breeds revealed 6 potential single-nucleotide polymorphisms ( 1 in exon 1 and 5 in intron 1), which were validated in different buffalo populations. This comparative analysis provides basic information for future studies of different buffalo herds using the
\end{abstract}


position candidate gene approach, quantitative trait loci analysis, and polymorphisms associated with growth traits.

Key words: 3-D screening; BAC library; Bubalus bubalis; Somatostatin gene; Pyrosequencing

\section{INTRODUCTION}

The somatostatin gene (SST) has been described in all vertebrates as one of the most important genes responsible for growth, fat deposition, and nutrient absorption. This gene influences growth, mainly by inhibiting different hormone secretion pathways. SST was originally described as a hypothalamic peptide that inhibits the secretion of growth hormone, negatively regulating growth (Brazeau et al., 1973). Various studies have shown that SST also inhibits peptides outside of the central nervous system, such as those found in the gastrointestinal tract (gastrin, secretin, and ghrelin) and pancreas (glucagon and insulin), in addition to those in the anterior pituitary gland (prolactin and thyrotropin) (Lloyd et al., 1997; Strowski et al., 2000; Luque et al., 2006).

SST is expressed by neuroendocrine, inflammatory, and immune cells in response to neuropeptides, cytokines, and growth factors (Reichlin, 1983). The presence of SST in a variety of endocrine and non-endocrine tissues, such as the placenta, pancreas, stomach, kidney, liver, lung, and intestinal tract, reflects its multiple biological functions (Patel, 1999; Møller et al., 2003). The role of this protein has been related to the regulation of acid gastric secretion, which controls digestion and absorption rates, influencing feed conversion, growth, and adiposity traits (Colturi et al., 1984; Lloyd et al., 1997; Luque et al., 2006). In cattle, SST was also found to be related to the expression of fertility genes and oocyte maturation rates (Moaeen-ud-Din et al., 2009).

Polymorphisms in the SST gene have been associated with growth traits in cattle (Morsci et al., 2006; Gao et al., 2011) and goat (Jin et al., 2011). Additionally, Kim et al. (2003) and Cai et al. (2004) identified the SST gene as a positional candidate in cattle for detecting quantitative trait loci affecting growth traits, including marbling, carcass weight, quality, and yield grades in Bos indicus $\mathrm{x}$ Bos taurus backcross and $\mathrm{F}_{2}$ progeny.

The river buffalo Bubalus bubalis holds great promise and potential for animal agriculture, playing an important role in the worldwide economy because of its high-quality milk and meat production. Genome analysis methods have advanced significantly in the last decade and now include genomic tools such as the whole genome radiation hybrid panel used for genome mapping (Amaral et al., 2007, 2008) and the construction of a Murrah breed BAC library for resequencing of specific regions from the genome, as well as the development of high-density physical maps (Stafuzza et al., 2012). Recently, the genome sequence of the Mediterranean breed was publicly released by the National Center for Biotechnology Information database (NCBI - http://www.ncbi.nlm.nih.gov/assembly/67671).

Because few studies have examined the SST gene in river buffalo, we characterized the structure of this gene in the Murrah breed using next-generation sequencing of a BAC clone and performed comparative analysis of the DNA coding and amino acid sequences against those from others mammals and chicken. 


\section{MATERIAL AND METHODS}

\section{Bacterial artificial chromosome library screening}

The river buffalo BAC library was screened (3-D screening method) by polymerase chain reaction (PCR) using the oligonucleotide primers forward 5'-CATGTTTACGGTTG CGAAAGG-3' and reverse 5'-GGGTCTTATTGAGGATTGGAG-3' designed using the Primer3web version 4.0.0 (http://bioinfo.ut.ee/primer3/), based on the SST gene sequence from Bos taurus UMD_3.1 reference assembly (GenBank accession No. AC_000158.1, 80,250,205$80,251,648)$.

The 3-D screening of the library was carried out in 3 steps. The first step was performed with 17 superpools, where each superpool contained BAC clones from 8 384-well plates. In the second step, 8 single pools, representing BAC clones from each of the 8 plates in the positive superpool, were screened. Finally, the pooled row and column BAC clones from the positive plate were screened. The intersection of the row and column identified the location of the positive BAC clone for the SST gene.

PCRs included: $10 \mathrm{mM}$ Tris- $\mathrm{HCl}, 1.5 \mathrm{mM} \mathrm{MgCl}, 50 \mathrm{mM} \mathrm{KCl}, 10 \mathrm{mM}$ dNTPs, 0.2 $\mathrm{mM}$ of each primer, $0.5 \mathrm{U}$ AmpliTaq Gold polymerase (Life Technologies ${ }^{\mathrm{TM}}$, Carlsbad, CA, USA), and $2 \mu \mathrm{L}$ BAC DNA in a $25-\mu \mathrm{L}$ reaction volume. Amplification conditions were as follows: initial denaturation at $94^{\circ} \mathrm{C}$ for $10 \mathrm{~min}$, followed by 35 cycles at $94^{\circ} \mathrm{C}$ for $30 \mathrm{~s}$ (denaturation), $50^{\circ} \mathrm{C}$ for $30 \mathrm{~s}$ (annealing), $72^{\circ} \mathrm{C}$ for $30 \mathrm{~s}$ (extension), and final extension at $72^{\circ} \mathrm{C}$ for 7 $\mathrm{min}$. The PCR products were electrophoresed on $\%$ agarose gels in $1 \mathrm{X}$ TBE buffer containing $0.25 \mu \mathrm{g} / \mathrm{mL}$ ethidium bromide and photographed under UV light.

\section{Isolation of BAC DNA}

The positive clone for the SST gene was grown in $50 \mathrm{~mL}$ Luria-Bertani medium containing $12.5 \mu \mathrm{g} / \mathrm{mL}$ chloramphenicol. The BAC DNA was purified using the PhasePrep ${ }^{\mathrm{TM}}$ BAC DNA Kit (Sigma-Aldrich, St. Louis, MO, USA) as described by the manufacturer. Briefly, clones were harvested by centrifugation at $5000 \mathrm{~g}$ for $10 \mathrm{~min}$. The supernatant was removed and the pellet was resuspended in $250 \mu \mathrm{L}$ solution containing RNase and $250 \mu \mathrm{L}$ lysis components followed by the addition of $250 \mu \mathrm{L}$ neutralization solution. The sample was incubated on ice for $5 \mathrm{~min}$ and centrifuged at $16,000 \mathrm{~g}$ for $5 \mathrm{~min}$ at $4^{\circ} \mathrm{C}$. The supernatant was transferred to a $2-\mathrm{mL}$ microcentrifuge tube and $450 \mu \mathrm{L}$ isopropanol was added. Nucleic acids were collected by centrifugation at $16,000 \mathrm{~g}$ for $20 \mathrm{~min}$ at $4^{\circ} \mathrm{C}$. The pellet was washed with $100 \mu \mathrm{L}$ $70 \%$ ethanol and followed by addition of $500 \mu \mathrm{L}$ elution solution.

Endotoxins and other impurities were removed by the addition of $100 \mu \mathrm{L}$ endotoxin removal solution followed by incubation on ice for $5 \mathrm{~min}$ and $37^{\circ} \mathrm{C}$ for $5 \mathrm{~min}$. The clear upper phase containing the BAC DNA was transferred to another 2-mL microcentrifuge tube followed by the addition of $540 \mu \mathrm{L}$ DNA precipitation solution and centrifugation at $16,000 \mathrm{~g}$ for $20 \mathrm{~min}$ at $4^{\circ} \mathrm{C}$. The supernatant was removed and the pellet was washed with $150 \mu \mathrm{L} 70 \%$ ethanol. The sample was centrifuged at $16,000 \mathrm{~g}$ for $20 \mathrm{~min}$ at $4{ }^{\circ} \mathrm{C}$. The supernatant was discarded and the BAC DNA was eluted in $100 \mu \mathrm{L}$ TE buffer.

The DNA concentration was determined using a NanoDrop spectrophotometer (Thermo Scientific, Waltham, MA, USA) and adjusted to $100 \mathrm{ng} / \mu \mathrm{L}$. An additional PCR with the purified DNA was performed as described to confirm amplification of the SST gene. 


\section{BAC DNA sequencing and bioinformatic analysis}

BAC DNA was sequenced by next-generation sequencing using 454-pyrosequencing - GS FLX Titanium chemistry (Roche, Basel, Switzerland) performed at the 454 Sequencing Center (Branford, CT, USA). Sequence data was assembled using the GS De Novo Assembler version 2.6 (Roche).

Repetitive DNA elements in the DNA sequence were identified using RepeatMasker (http://www.repeatmasker.org/). The Augustus software was used to predict genes from the masked nucleotide sequence (http://bioinf.uni-greifswald.de/augustus/). The predicted gene sequence was aligned against the NCBI reference mRNA sequences from Bos taurus using BLAST tools (http://blast.ncbi.nlm.nih.gov/Blast.cgi) and the predicted peptide sequence was aligned against non-redundant protein sequences by BLASTp (protein-protein BLAST) to verify homology among other species and identify the predicted gene.

The coordinates of exons, introns, 5'-untranslated region (UTR) and 3'UTR were obtained performing an alignment between the BAC DNA sequence from the Murrah breed against the predicted gene sequence available for the Mediterranean breed on NCBI (http://www.ncbi.nlm.nih.gov/assembly/67671).

VISTA plots were generated using wgVISTA alignment (http://genome.lbl.gov/cgibin/WGVistaInput) with the bovine chromosome 1 genomic scaffold (GenBank accession No. NW_003103812.1) to reveal the relative nucleotide identity between river buffalo and bovine.

Clustal Omega software (http://www.ebi.ac.uk/Tools/msa/clustalo/) was used to align the coding gene sequences and amino acids sequences from the following species: B. bubalis, B. taurus, Ovis aries, Capra hircus, Sus scrofa, Equus caballus, Homo sapiens, Rattus norvegicus, Mus musculus, and Gallus gallus. Additionally, we performed an alignment of the river buffalo BAC DNA sequence from the Murrah breed against the predicted gene sequence available for the Mediterranean breed on NCBI (GenBank accession No. NW_005785332.1, unplaced genomic scaffold scf7180021617452, UMD_CASPUR_WB_2.0).

\section{RESULTS}

The screening of the river buffalo BAC library resulted in the identification of 1 positive clone for the SST gene. The 454/Roche GS FLX sequencer generated a total of 4012 reads with an average read length of 707 nucleotides arranged in 1 contig of 72,489 nucleotides, providing $38.7 \mathrm{x}$ coverage, an $\mathrm{N} 50$ value of $72.49 \mathrm{~kb}$, and $99.87 \% \mathrm{Q} 40_{+}$. The BAC clone sequence was deposited in GenBank under accession No. KJ635884.

The gene prediction by the Augustus software detected only 1 gene in the BAC DNA sequence from the Murrah breed. Alignment of the predicted gene against the NCBI reference mRNA sequences from $B$. taurus revealed $99 \%$ identity and $100 \%$ coverage with $B$. taurus SST mRNA (GenBank accession No. NM_173960.1). The predicted peptide alignment against non-redundant protein sequences from the $B$. taurus database revealed $99 \%$ identity and $100 \%$ coverage with the B. taurus SST precursor protein (GenBank accession No. NP_776385.1).

Alignment of the Murrah BAC sequence against the predicted gene for the Mediterranean breed (GenBank accession No. NW_005785332.1) established the coordinates of the SST gene from nucleotide 2038 to nucleotide 3518, with a total length of $1481 \mathrm{bp}$. Organization of the gene was as follows: 5'UTR (135 bp), exon 1 (139 bp), intron 1 (839 bp), exon 2 
(212 bp), and 3'UTR (156 bp), showing an exon/intron size ratio of 1:2.39 and the CG level of $49.34 \%$. The coding sequence contained a total of 351 nucleotides encoding 116 amino acids.

Comparative analysis using wgVISTA alignment between the SST gene from buffalo and bovine (chromosome 1 genomic scaffold - GenBank accession No. NW_003103812.1) showed $98.1 \%$ conservation of the 5 'UTR region, $99.3 \%$ on exon $1,98.1 \%$ on intron $1,99.5 \%$ on exon 2 , and $100 \%$ on the 3 'UTR (Figure 1).

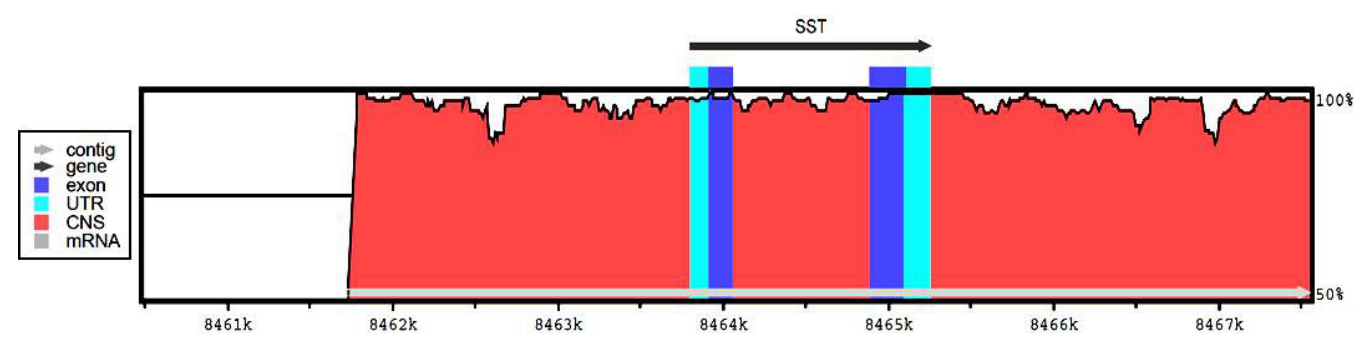

Figure 1. wgVISTA plot obtained from the alignment of the Murrah BAC nucleotide sequence and the bovine chromosome 1 genomic scaffold (GenBank accession No. NW_003103812.1), showing genomic conservation (CNS) higher than $98 \%$ between both sequences, indicated in red. The black arrow represents the SST gene. Exons are indicate by dark blue blocks while the 5'UTR and 3'UTR are indicated with light blue blocks.

Regarding the presence of repetitive elements in the river buffalo SST gene, the RepeatMasker tool identified only 1 microsatellite of $60 \mathrm{bp}$ located on intron 1 of the gene showing the repeat unit $(\mathrm{TCT})_{\mathrm{n}}$.

Multiple alignment of the buffalo SST gene coding sequence showed $99 \%$ identity with other bovids, including cattle (GenBank accession No. NM_173960.1), sheep (GenBank accession No. NM_001009196.1), and goat (GenBank accession No. NM_001287555.1), 97\% with pig and horse (GenBank accession No. NM_001009583.1 and XM_001499693.4, respectively), 95\% with human (GenBank accession No. NM_001048.3), 91\% with rat (GenBank accession No. NM_012659.1), 90\% with mouse (GenBank accession No. NM_009215.1), and 83\% with chicken (GenBank accession No. NM_205336.1) (Figure 2).

On the protein level, the amino acid sequence from the river buffalo revealed $100 \%$ identity with the sequences described in goat (GenBank accession No. NP_001274484.1), sheep (GenBank accession No. NP_001009196.1), horse (GenBank accession No. XP_001499743.1), and pig (GenBank accession No. NP_001009583.1). Cattle (GenBank accession No. NP_776385) and human (GenBank accession No. NP_001039) showed 99\% identity on the protein level, while rat and mouse (GenBank accession No. NP_036791.1 and NP_033241.1, respectively) showed 97\% and chicken (GenBank accession No. NP_990667.1) showed $88 \%$ identity (Figure 3 ).

Alignment of the SST gene sequence from the Murrah breed against the predicted gene sequence for the Mediterranean breed (GenBank accession No. NW_005785332.1) revealed $99 \%$ identity. Six nucleotide substitutions (1 on exon 1 and 5 on intron 1) and 1 deletion (intron 1) were observed in the Murrah breed sequence at the following positions: exon $1($ g. 207C $>$ A) and intron 1 (g.371T $>$ C, g.456delT, g.467T $>$ C, g.610A $>$ C, g.906A $>$ C, and g. $999 \mathrm{G}>\mathrm{A})$.

\section{DISCUSSION}




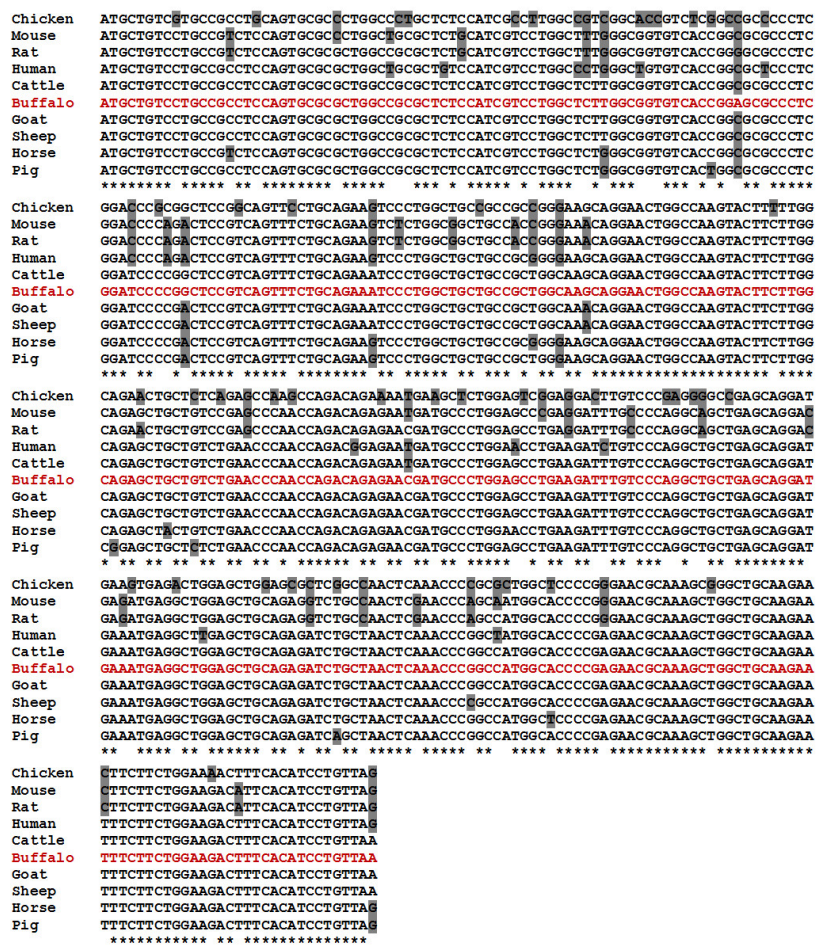

Figure 2. Multispecies alignment using the Clustal Omega software showing the percentage identity among the buffalo SST gene coding sequence and cattle (GenBank accession No. NM 173960.1), sheep (GenBank accession No. NM_001009196.1), goat (GenBank accession No. NM_001287555.1), pig (ḠenBank accession No. NM_001009583.1), horse (GenBank accession No. XM 001499693.4), human (GenBank accession No. NM 001048.3), rat (GenBank accession No. NM_012659.1), mouse (GenBank accession No. NM_009215.1), and chicken (GenBank accession No. NM_205336.1). Nucleotides substitutions in relation to buffalo coding sequence are shaded.

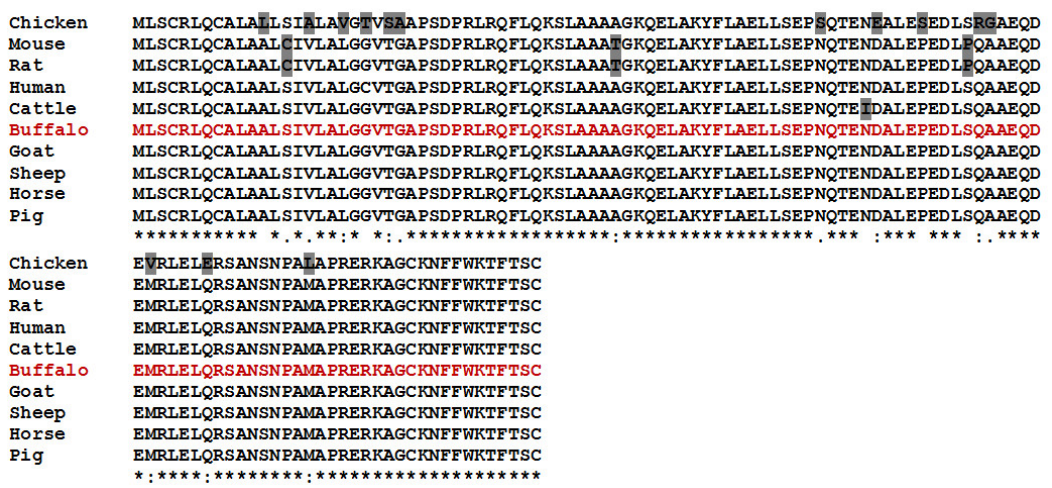

Figure 3. Multispecies alignment using the Clustal Omega software showing the percentage identity of buffalo SST amino acid sequence against the protein sequences from goat (GenBank accession No. NP 001274484.1), sheep (GenBank accession No. NP_001009196.1), horse (GenBank accession No. XP_001499743.1), pig (GenBank accession No. NP_001009583.1), cattle (GenBank accession No. NP_776385), human (GenBank accession No. NP 001039), rat (GenBank accession No. NP 036791.1), mouse (GenBank accession No. NP 033241.1), and chicken (GenBank accession No. NP_990667.1). Amino acids substitutions in relation to the buffalo sequence are shaded. 
The river buffalo BAC library is a valuable tool for investigating genome organization and chromosome evolution in closely related species as well as for the resequencing of target regions of the genome, providing an accurate assembly of the sequences. In this study, we isolated $1 \mathrm{BAC}$ clone from the Murrah BAC library containing the SST gene. We determined that the buffalo SST gene was a total length of $1481 \mathrm{bp}$, organized into 2 exons (exon 1 and 2) and 1 intron (intron 1) as well as the complete $5^{\prime}$ and $3^{\prime}$ UTR sequences. The exon/intron size ratio of 1:2.39 observed from river buffalo was the same as that observed in cattle, sheep, and goat.

The difference in the total length of the SST gene observed in buffalo when compared with other species appears to be the result of differences found only in the size of intron 1 and UTRs. The buffalo intron 1 also showed 1 microsatellite sequence of $60 \mathrm{bp}$, which was also observed in all other bovids (cattle, sheep, and goat) but not in pig, horse, human, rodents, and chickens.

Multiple alignments of the buffalo SST gene coding sequences showed conservation in the size of both exons, exon 1 (139 bp) and exon 2 (212 bp), in all species analyzed in this study. Both exons from the buffalo gene showed $99 \%$ identity with the exons from other bovids (cattle, sheep, and goat). Interestingly, on the protein level, the buffalo somatostatin protein showed $100 \%$ identity with sheep and goat and only $99 \%$ identity with cattle, resulting from 1 nonsynonymous substitution that occurred on cattle exon 2 (Ile65Asn).

Additionally, comparison of the Murrah breed against the predicted gene sequence for the Mediterranean breed revealed 6 potential SNPs that could be used to determine the genetic structure of these 2 buffalo breeds.

Characterization of the river buffalo SST gene confirmed the high conservation of its structure when compared with several vertebrates. The comparative analysis described in this study provides basic information for future studies in different river buffalo populations, possibly using the position candidate gene approach, quantitative trait loci analysis, and polymorphisms associated with growth traits.

\section{ACKNOWLEDGMENTS}

Research supported by Fundação de Amparo à Pesquisa do Estado de São Paulo (grant \#2011/11889-3 to M.E.J. Amaral and \#2011/02478-0 to N.B. Stafuzza) and Coordenação de Aperfeiçoamento de Pessoal de Nivel Superior (master fellowship to M.M. Borges).

\section{REFERENCES}

Amaral ME, Owens KE, Elliott JS, Fickey C, et al. (2007). Construction of a river buffalo (Bubalus bubalis) wholegenome radiation hybrid panel and preliminary RH mapping of chromosomes 3 and 10. Anim. Genet. 38: 311-314.

Amaral ME, Grant JR, Riggs PK, Stafuzza NB, et al. (2008). A first generation whole genome RH map of the river buffalo with comparison to domestic cattle. BMC Genomics 9: 631.

Brazeau P, Vale W, Burgus R, Ling N, et al. (1973). Hypothalamic polypeptide that inhibits the secretion of immunoreactive pituitary growth hormone. Science 179: 77-79.

Cai L, Taylor J, Smyth K, Findeisen B, et al (2004). Quantitative Trait Loci and Somatostatin. United States Patent Application No. 20040018511. Available at [http://www.google.com/patents/US20040018511]. Accessed March 18, 2014.

Colturi TJ, Unger RH and Feldman M (1984). Role of circulating somatostatin in regulation of gastric acid secretion, gastrin release, and islet cell function. Studies in healthy subjects and duodenal ulcer patients. J. Clin. Invest. 74: 417-423.

Gao L, Zan LS, Wang HB, Hao RJ, et al. (2011). Polymorphism of somatostatin gene and its association with growth traits 
in Chinese cattle. Genet. Mol. Res. 10: 703-711.

Jin QJ, Sun JJ, Fang XT, Zhang CL, et al. (2011). Molecular characterization and polymorphisms of the caprine Somatostatin (SST) and SST Receptor 1 (SSTR1) genes that are linked with growth traits. Mol. Biol. Rep. 38: 31293135.

Kim JJ, Farnir F, Savell J and Taylor JF (2003). Detection of quantitative trait loci for growth and beef carcass fatness traits in a cross between Bos taurus (Angus) and Bos indicus (Brahman) cattle. J. Anim. Sci. 81: 1933-1942.

Lloyd KC, Amirmoazzami S, Friedik F, Chew P, et al. (1997). Somatostatin inhibits gastrin release and acid secretion by activating sst2 in dogs. Am. J. Physiol. 272: G1481-G1488.

Luque RM, Gahete MD, Hochgeschwender U and Kineman RD (2006). Evidence that endogenous SST inhibits ACTH and ghrelin expression by independent pathways. Am. J. Physiol. Endocrinol. Metab. 291: E395-E403.

Moaeen-ud-Din M, Malik N and Yang LG (2009). Somatostatin can alter fertility genes expression, oocytes maturation, and embryo development in cattle. Anim. Biotechnol. 20: 144-150.

Møller LN, Stidsen CE, Hartmann B and Holst JJ (2003). Somatostatin receptors. Biochim. Biophys. Acta 1616: 1-84.

Morsci NS, Schnabel RD and Taylor JF (2006). Association analysis of adiponectin and somatostatin polymorphisms on BTA1 with growth and carcass traits in Angus cattle. Anim. Genet. 37: 554-562.

Patel YC (1999). Somatostatin and its receptor family. Front. Neuroendocrinol. 20: 157-198.

Reichlin S (1983). Somatostatin. N. Engl. J. Med. 309: 1495-1501.

Stafuzza NB, Abbey CA, Gill CA, Womack JE, et al. (2012). Construction and preliminary characterization of a river buffalo bacterial artificial chromosome library. Genet. Mol. Res. 11: 3013-3019.

Strowski MZ, Parmar RM, Blake AD and Schaeffer JM (2000). Somatostatin inhibits insulin and glucagon secretion via two receptors subtypes: an in vitro study of pancreatic islets from somatostatin receptor 2 knockout mice. Endocrinology 141: 111-117. 